\title{
Optimal Ordering and Transfer Policy for an Inventory System with Time Dependent Holding Cost and Three Component Demand Rate
}

\author{
Bindu Vaish \\ D. N. College, Meerut \\ Garima Garg \\ RKGIT, Ghaziabad \\ E-mail: garima6982@gmail.com
}

Received: December 31, 2010 Accepted: January 13, 2011 doi:10.5539/jmr.v3n2p212

\begin{abstract}
This paper deals with an ordering-transfer policy to determine the retailer's optimal order quantity and the number of transferred units from the warehouse to the display area. It is assumed that the amount of display space is limited and the demand rate depends on the selling price, instantaneous displayed stock level and the frequency of advertisement. The objective is to maximize the average profit per unit time yielded by the retailer. Numerical examples are presented to illustrate the model and the sensitivity analysis is also reported.
\end{abstract}

Keywords: Three component demand rate, Time dependent holding cost, Transfer policy

\section{Introduction}

An inventory model usually considers a case in which depletion of inventory is caused by a constant or stock dependent demand rate, but in real-life-situations, a customer may buy taking factors such as selling price, inventory level, seasonality and so on into consideration.

A product is promoted now-a-days in the society through advertisement in modern electronic/mass media and/ or by decorative and attractive display in showrooms/shops. Glamorous display in large numbers with the help of modern lights and electronic arrangements attracts people to buy more units. As Levin et al. (1972) puts it "it is common believe that large piles of consumer goods displayed in a supermarket will lead the customer to buy more". Recent market research also recognizes this relationship and thus many researchers have focused on the analysis of the inventory control which describes the demand rate dependent on the displayed stock level. Again frequent advertisement through TV, Radio, Magazines, Newspapers, sales representatives, etc., also affects the demand of the commodity. But for selecting an item for use its selling price is one of the decisive factors. It is a common practice that the lower selling price of an item causes a higher demand of that item where as a higher selling price has the reverse effect. Therefore we conclude that the demand of an item may be a function of frequency of advertisement, selling price of an item and instantaneous displayed stock level.

Gupta and Vrat (1986) assumed the demand rate as a function of initial stock level. Mandal and Phaujdar (1989) developed a production inventory model for deteriorating items with uniform rate of production and linearly stock-dependent demand. Datta and Pal (1990) and Padmanabhan and Vrat (1995) concentrated on the situation that defined the demand rate as a polynomial function dependent on the instantaneous stock level. Burwell et al. (1997) developed an economic lot size model where demand is considered to be dependent on price. Teng and Chang (2005) established an economic production quantity model for deteriorating items where the demand rate depends on the displayed stock level and the selling price per unit. Pal et al. (2006) considered the problem of determining the lot size with the demand rate dependent on displayed stock level, selling price of an item and frequency of advertisement. Gupta et al. (2007) investigated an inventory model by considering a three component demand rate i.e. rate is dependent on selling price, frequency of advertisement and displayed stock level. Mo et al. (2009) explored the inventory replenishment policy for items in which demand is sensitive to stock and selling price.

In most of the models the holding cost per unit item is taken as a constant. However in real life situation the cost to stock the product increases over time. This is particularly true in the storage of deteriorating and perishable items such as food products. The longer these products are kept in storage, the more sophisticated the storage facilities and services needed and therefore the higher holding cost. The variability in the holding cost was first introduced by Muhlemann and Spanopoulous (1980). They developed an EOQ model with constant demand rate and expressing the holding cost as a percentage of the average value of capital invested in the stock. Weiss (1982) studied the inventory system treating holding cost per unit as a non-linear function of the length of time for which the item was held in stock. Goh (1994) and Giri and Chaudhuri (1998) developed an EOQ model with non-liner holding cost. Shao et al. (2000) determined the optimal target for a process with multiple markets and variable holding cost. Alfares (2007) studied a stock dependent demand 
model with storage time dependent holding cost by using profit maximization objective. Urban (2008) investigated inventory model with discretely variable holding cost.

In the busy markets like Super markets, Municipality markets, etc., the storage area of items is limited. When an attractive price discount for bulk purchase is available or demand of items is very high or there are some problems in frequent procurement, management decides to purchase a large amount of items at a time, but these items cannot be stored in the existing display area (DA) located at busy market place. In such a situation, for storing the excess items management has to hire a separate large warehouse on rental basis which may be a little away from DA. It's assumed that the holding cost of the item in separate warehouse is greater than that in DA. The items are stored first in separate warehouse and a fixed amount is transferred to DA at equal interval of periods. The demand of items is met up at DA only. In past, few researchers have analyzed extensively the issue of two warehouse inventory. Sarma (1983) developed a deterministic inventory model with two levels of storage and infinite production rate. Murdeshwar and Sathe (1985) made an extension to the case of finite production rate. Pakkala and Achary (1991) developed a two warehouse probabilistic order level inventory model for deteriorating items. Goswami and Chaudhuri (1992) considered two level storage models with and without shortages allowing linearly increasing time dependent demand. Ishii and Nose (1996) investigated the optimal ordering policies for a perishable product with different type of customer's priority, different selling price specified and the owned warehouse capacity constraint. Bhunia and Maiti (1998) studied a two-warehouse inventory model for deteriorating items considering linearly time-dependent demand and shortage (for single period). Kar et al. (2001) developed a two storage inventory model with linearly time-dependent demand over finite time horizon under inflation. Yang (2004) considered a two-warehouse inventory model under inflation for constantly deteriorating items with constant demand rate and completely back logged shortages. Wee (2005) developed two-warehouse inventory model under inflation with partial back-ordering \& weibull distribution deteriorating. Dey et al. (2008) proposed a two storage inventory problem with dynamic demand under inflation and time value of money over finite time horizon. Goyal \& Chang (2009) developed an ordering-transfer inventory model to determine optimal order quantity and the number of transfers per order from the warehouse to the display area. It is assumed that the amount of display space is limited and the demand rate depends on the display stock level.

The present paper is an extension of Goyal and Chang (2009). They proposed an ordering transfer inventory model for an infinite time horizon with the demand rate that is influenced by stock level. In the present paper an ordering transfer inventory model is considered with demand rate that is influenced by selling price, instantaneously displayed stock level and frequency of advertisement. The model is developed for finite planning horizon. A time dependent holding cost for the rented warehouse is considered in the model. Numerical examples are provided to illustrate the optimization procedure. In addition the sensitivity analysis of the optimal solution with respect to parameters of the system is carried out.

\section{Assumptions and Notation}

\subsection{Assumptions}

The following assumptions are adopted:

1. Shortages are not allowed.

2. To avoid a negative impression and to indicate the display space limit, we define the maximum allowable number of displayed stocks in the display area as $I_{m}$

3. The lead time between the retailer and the supplier is zero.

4. The time to transfer items from the warehouse to the display area is zero.

5. The ordering-transfer policy adopted in the paper is as follows:

the retailer orders quantity Q per order from a supplier and stocks these items in the warehouse. The items are transferred from the warehouse to the display area in equal lots of q units until the inventory level in the warehouse falls to zero.

\subsection{Notations}

The following notations are used:

1. $h_{1}$ is the unit carrying cost per item in the warehouse

2. $h$ is the unit carrying cost per item in the display area, with $h<h_{1}$

3. $I_{m}$ is the maximum allowable number of displayed stocks in the display area

4. $s$ is the unit selling price of the product per unit 
5. $c_{1}$ is the unit purchasing cost

6. A is the cost of placing per order

7. $A_{t}$ is the fixed cost per transfer from the rented warehouse to the display area

8. $\mathrm{T}$ is the replenishment cycle time in the warehouse

9. $\mathrm{n}$ is the integer number of transfers from the warehouse to the display area per order

10. $t_{1}$ is the replenishment cycle time in the display area

11. Q is the order quantity placed on the supplier

12. $\mathrm{q}$ is the quantity per transfer from the warehouse to the display area, where $0 \leq q \leq 1$

13. $\mathrm{I}(\mathrm{t})$ is the inventory level at any time $\mathrm{t}$ in the display area, which is always less than or equal to $I_{m}$

14. $\mathrm{B}$ is the buffer stock of the items in the display area regarding the transfer of $\mathrm{q}$ items from the warehouse to the display area

15. $A_{D}$ is frequency of advertisements in the cycle.

16. $\alpha_{1}$ is the scale parameter for an increment in holding cost in rented warehouse.

17. $D\left(A_{D}, s, I(t)\right)$ is the demand rate, which is depending on frequency of advertisement, unit selling price and instantaneous displayed stock level Demand rate $D\left(A_{D}, s, I(t)\right)=A_{D}^{\beta}\left(a-b s^{\alpha}+c I(t)\right), 0<t \leq t_{1}$ Where $a, b, c, \beta, \alpha>$ 0

\section{Mathematical Models}

\subsection{The total cost per unit cycle in the rented warehouse}

The retailer orders Q items per order from a supplier and stocks these items in the warehouse. The quantity q per transfer is transferred from the warehouse to the display area until the inventory level in the warehouse falls to zero. Thus, we get $\mathrm{Q}=$ nq. The total cost over the period $[0, \mathrm{~T}]$ in the warehouse consists of

(i) The cost of placing orders $=\mathrm{A}$

(ii) The cost of stock holding, $C_{w h}=\sum_{j=1}^{n-1}\left\{h_{1}+\alpha_{1}(j-1) t_{1}\right\}(n-j) q t_{1}$

$$
\begin{gathered}
=\sum_{j=1}^{n-1} h_{1}(n-j) q t_{1}+\sum_{j=1}^{n-1} \alpha_{1}(j-1)(n-j) q t_{1}^{2} \\
=\frac{1}{6} n(n-1) q t_{1}\left\{3 h_{1}+(n-2) \alpha_{1} t_{1}\right\} \ldots
\end{gathered}
$$

\subsection{The total cost per unit cycle in the display area}

At time $\mathrm{t}=0$, the inventory level $I(t)$ reaches the top $q+B\left(q+B \leq I_{m}\right)$ because the items are transferred from the warehouse to the display area. The inventory level then gradually depletes to B at the end of the cycle. A graphical representation of this inventory system is depicted. (Figure 1)

The differential equation expressing the inventory level at any time $\mathrm{t}$ can be written as follows:

$$
\frac{d I(t)}{d t}=-D\left(A_{D}, s, I(t)\right) 0 \leq t \leq t_{1}
$$

Where $D\left(A_{D}, s, I(t)\right)=A_{D}^{\beta}\left(a-b s^{\alpha}+c I(t)\right)$

$$
\frac{d I(t)}{d t}=-A_{D}^{\beta}\left(a-b s^{\alpha}+c I(t)\right) 0 \leq t \leq t_{1} \ldots
$$

Using boundary condition $I\left(t_{1}\right)=B$ we have

$$
I(t)=B e^{A_{D}^{\beta} c\left(t_{1}-t\right)}+\frac{\left(a-b s^{\alpha}\right)}{c}\left\{e^{A_{D}^{\beta} c\left(t_{1}-t\right)}-1\right\} \cdots
$$

The total cost over the period $\left(0, t_{1}\right)$ consists of 
(i) Fixed cost per transfer $=A_{t}$

(ii) Holding cost, $C_{h}=h \int_{0}^{t_{1}} I(t) d t$

$$
\begin{aligned}
& =h \int_{0}^{t_{1}}\left\{B e^{A_{D}^{\beta} c\left(t_{1}-t\right)}+\frac{\left(a-b s^{\alpha}\right)}{c}\left\{e^{A_{D}^{\beta} c\left(t_{1}-t\right)}-1\right\}\right\} d t \\
= & h\left[\frac{1}{A_{D}^{\beta} c}\left\{e^{A_{D}^{\beta} c t_{1}}-1\right\}\left\{B+\frac{\left(a-b s^{\alpha}\right)}{c}\right\}-\frac{\left(a-b s^{\alpha}\right)}{c} t_{1}\right] \ldots
\end{aligned}
$$

(iii) The revenue per cycle is $\left(s-c_{1}\right) \int_{0}^{t_{1}} D\left(A_{D}, s, I(t)\right) d t$

$$
\begin{gathered}
=\left(s-c_{1}\right) \int_{0}^{t_{1}}\left[A_{D}^{\beta}\left(a-b s^{\alpha}+c I(t)\right)\right] d t \\
=\left(s-c_{1}\right) A_{D}^{\beta}\left(a-b s^{\alpha}\right) t_{1}+\left(s-c_{1}\right) A_{D}^{\beta} c \int_{0}^{t_{1}}\left\{B e^{A_{D}^{\beta} c\left(t_{1}-t\right)}\right. \\
\left.+\frac{\left(a-b s^{\alpha}\right)}{c}\left\{e^{A_{D}^{\beta} c\left(t_{1}-t\right)}-1\right\}\right\} d t \\
=\left(s-c_{1}\right) A_{D}^{\beta}\left(a-b s^{\alpha}\right) t_{1}+\left(s-c_{1}\right) A_{D}^{\beta} c \\
{\left[\frac{1}{A_{D}^{\beta} c}\left\{e^{A_{D}^{\beta} c t_{1}}-1\right\}\left\{B+\frac{\left(a-b s^{\alpha}\right)}{c}\right\}-\frac{\left(a-b s^{\alpha}\right)}{c} t_{1}\right] \ldots}
\end{gathered}
$$

Applying boundary condition in equation (3) It is obtained and $I(0)=q+B$

$$
\begin{gathered}
q+B=B e^{A_{D}^{\beta} c t_{1}}+\frac{\left(a-b s^{\alpha}\right)}{c}\left[e^{A_{D}^{\beta} c t_{1}}-1\right] \\
q=\left\{B+\frac{\left(a-b s^{\alpha}\right)}{c}\right\}\left(e^{A_{D}^{\beta} c t_{1}}-1\right) \cdots
\end{gathered}
$$

From equation (1) and equation (6) the cost of stock holding in the warehouse is

$$
C_{w h}=\frac{1}{6} n(n-1)\left\{B+\frac{\left(a-b s^{\alpha}\right)}{c}\right\}\left(e^{A_{D}^{\beta} c t_{1}}-1\right) t_{1}\left\{3 h_{1}+(n-2) \alpha_{1} t_{1}\right\} \ldots
$$

Hence, the total profit $T P$ over the period $[0, T]$ is

$T P(s, B)=$ revenue - (total cost in the warehouse) - (total cost in the display area)

$$
\begin{gathered}
=-A-n A_{t}+n h \frac{\left(a-b s^{\alpha}\right)}{c} t_{1}+\left\{B+\frac{\left(a-b s^{\alpha}\right)}{c}\right\}\left(e^{A_{D}^{\beta} c t_{1}}-1\right)\left[n\left(s-c_{1}\right)\right. \\
\left.-\frac{1}{2} n(n-1) h_{1} t_{1}-\frac{1}{6} n(n-1)(n-2) \alpha_{1} t_{1}^{2}-\frac{n h}{A_{D}^{\beta} c}\right] \ldots
\end{gathered}
$$

Hence, the average profit per unit time is

$A P(s, B)=\frac{T P(s, B)}{T}$ where $T=n t_{1}$

$$
\begin{gathered}
=-\frac{A}{n t_{1}}-\frac{A_{t}}{t_{1}}+h \frac{\left(a-b s^{\alpha}\right)}{c}+\left\{B+\frac{\left(a-b s^{\alpha}\right)}{c}\right\}\left(e^{A_{D}^{\beta} c t_{1}}-1\right)\left[\frac{\left(s-c_{1}\right)}{t_{1}}\right. \\
\left.-\frac{1}{2}(n-1) h_{1}-\frac{1}{6}(n-1)(n-2) \alpha_{1} t_{1}-\frac{h}{A_{D}^{\beta} c t_{1}}\right] \ldots
\end{gathered}
$$

\section{Solution Procedure}

According to equation (9), $A P(s, B)$ is a function of $s$ and $B$. For fixed $\mathrm{n}$ and $t_{1}$, the effect of sand $B$ on the average profit per unit time will be examined. Taking the first and second partial derivative of $A P(s, B)$ with respect to $s$ and $B$, we obtain

$$
\frac{\partial A P}{\partial B}=\left(e^{A_{D}^{\beta} c t_{1}}-1\right)\left[\frac{\left(s-c_{1}\right)}{t_{1}}-\frac{(n-1)}{2} h_{1}-\frac{1}{6}(n-1)(n-2) \alpha_{1} t_{1}-\frac{h}{A_{D}^{\beta} c t_{1}}\right] \cdots
$$


And

$$
\begin{gathered}
\frac{\partial^{2} A P}{\partial B^{2}}=0 \\
\frac{\partial A P}{\partial s}=-\frac{h b \alpha}{c} s^{\alpha-1}-\frac{b \alpha}{c} s^{\alpha-1}\left(e^{A_{D}^{\beta} c t_{1}}-1\right)\left[\frac{\left(s-c_{1}\right)}{t_{1}}-\frac{(n-1)}{2} h_{1}-\frac{1}{6}(n-1)(n-2) \alpha_{1} t_{1}\right. \\
\left.-\frac{h}{A_{D}^{\beta} c t_{1}}\right]+\frac{1}{t_{1}}\left\{B+\frac{\left(a-b s^{\alpha}\right)}{c}\right\}\left(e^{A_{D}^{\beta} c t_{1}}-1\right) \ldots
\end{gathered}
$$

And $\frac{\partial^{2} A P}{\partial s^{2}}=-\frac{h b \alpha(\alpha-1)}{c} s^{\alpha-2}-\frac{b \alpha(\alpha-1)}{c} s^{\alpha-2}\left(e^{A_{D}^{\beta} c t_{1}}-1\right)\left[\frac{\left(s-c_{1}\right)}{t_{1}}-\frac{(n-1)}{2} h_{1}\right.$

$$
\begin{gathered}
\left.-\frac{1}{6}(n-1)(n-2) \alpha_{1} t_{1}-\frac{h}{A_{D}^{\beta} c t_{1}}\right]-\frac{2 b \alpha}{c t_{1}} s^{\alpha-1}\left(e^{A_{D}^{\beta} c t_{1}}-1\right) \ldots \\
\frac{\partial^{2} A P}{\partial s \partial B}=\frac{1}{t_{1}}\left(e^{A_{D}^{\beta} c t_{1}}-1\right) \ldots
\end{gathered}
$$

To maximize average profit per unit time $A P(s, B)$, the optimal values of sand $B$ can be obtained by solving the following equations simultaneously.

$$
\frac{\partial A P}{d s}=0 \text { and } \quad \frac{\partial A P}{d B}=0
$$

i.e. $\frac{\partial A P}{\partial B}=\left(e^{A_{D}^{\beta} c t_{1}}-1\right)\left[\frac{\left(s-c_{1}\right)}{t_{1}}-\frac{(n-1)}{2} h_{1}-\frac{1}{6}(n-1)(n-2) \alpha_{1} t_{1}-\frac{h}{A_{D}^{\beta} c t_{1}}\right]=0$

and $\frac{\partial A P}{\partial s}=-\frac{h b \alpha}{c} s^{\alpha-1}-\frac{b \alpha}{c} s^{\alpha-1}\left(e^{A_{D}^{\beta} c t_{1}}-1\right)\left[\frac{\left(s-c_{1}\right)}{t_{1}}-\frac{(n-1)}{2} h_{1}-\frac{1}{6}(n-1)(n-2) \alpha_{1} t_{1}\right.$

$$
\begin{gathered}
\left.-\frac{h}{A_{D}^{\beta} c t_{1}}\right]+\frac{1}{t_{1}}\left\{B+\frac{\left(a-b s^{\alpha}\right)}{c}\right\}\left(e^{A_{D}^{\beta} c t_{1}}-1\right)=0 \text { provided } r t-s^{2}=\left(\frac{\partial^{2} A P}{\partial B^{2}}\right)\left(\frac{\partial^{2} A P}{\partial s^{2}}\right)-\left(\frac{\partial^{2} A P}{\partial s \partial B}\right)^{2} \\
=-\left(\frac{\partial^{2} A P}{\partial s \partial B}\right)^{2}<0
\end{gathered}
$$

The results show that $A P(s, B)$ is a concave function of sand $B$ for fixed $\mathrm{n}$ and $t_{1}$. Therefore, there exists a unique value of sand $B$ such that $A P(s, B)$ is maximum.

\section{Special Cases}

\section{CASE 1:}

If $\beta=0$, then the demand rate reduces to $D\left(A_{D}, s, I(t)\right)=\left(a-b s^{\alpha}+c I(t)\right), \quad 0<t \leq t_{1}$ That is, the demand rate depends on unit selling price and instantaneous displayed stock level.

Hence, the inventory level at time $t$ is given by the differential equation:

$$
\frac{d I(t)}{d t}=-\left(a-b s^{\alpha}+c I(t)\right)
$$

Therefore,

$$
I(t)=B e^{c\left(t_{1}-t\right)}+\frac{\left(a-b s^{\alpha}\right)}{c}\left\{e^{c\left(t_{1}-t\right)}-1\right\}
$$

And the quantity per transfer from the warehouse to the display area is given by

$$
q=\left\{B+\frac{\left(a-b s^{\alpha}\right)}{c}\right\}\left(e^{c t_{1}}-1\right)
$$

and the average profit per unit time $A P(s, B)$ over the period $[0, \mathrm{~T}]$ is reduced to

$$
\begin{gathered}
A P(s, B)=-\frac{A}{n t_{1}}-\frac{A_{t}}{t_{1}}+h \frac{\left(a-b s^{\alpha}\right)}{c}+\left\{B+\frac{\left(a-b s^{\alpha}\right)}{c}\right\}\left(e^{c t_{1}}-1\right)\left[\frac{\left(s-c_{1}\right)}{t_{1}}\right. \\
\left.-\frac{1}{2}(n-1) h_{1}-\frac{1}{6}(n-1)(n-2) \alpha_{1} t_{1}-\frac{h}{c t_{1}}\right] \ldots
\end{gathered}
$$


Taking the first and second partial derivative of $A P(s, B)$ with respect to $s$ and $B$, we obtain

$$
\frac{\partial A P}{\partial B}=\left(e^{c t_{1}}-1\right)\left[\frac{\left(s-c_{1}\right)}{t_{1}}-\frac{(n-1)}{2} h_{1}-\frac{1}{6}(n-1)(n-2) \alpha_{1} t_{1}-\frac{h}{c t_{1}}\right] \ldots
$$

And

$$
\begin{gathered}
\frac{\partial^{2} A P}{\partial B^{2}}=0 \\
\frac{\partial A P}{\partial s}=-\frac{h b \alpha}{c} s^{\alpha-1}-\frac{b \alpha}{c} s^{\alpha-1}\left(e^{c t_{1}}-1\right)\left[\frac{\left(s-c_{1}\right)}{t_{1}}-\frac{(n-1)}{2} h_{1}-\frac{1}{6}(n-1)(n-2) \alpha_{1} t_{1}\right. \\
\left.-\frac{h}{c t_{1}}\right]+\frac{1}{t_{1}}\left\{B+\frac{\left(a-b s^{\alpha}\right)}{c}\right\}\left(e^{c t_{1}}-1\right) \ldots
\end{gathered}
$$

And $\frac{\partial^{2} A P}{\partial s^{2}}=-\frac{h b \alpha(\alpha-1)}{c} s^{\alpha-2}-\frac{b \alpha(\alpha-1)}{c} s^{\alpha-2}\left(e^{c t_{1}}-1\right)\left[\frac{\left(s-c_{1}\right)}{t_{1}}-\frac{(n-1)}{2} h_{1}\right.$

$$
\begin{gathered}
\left.-\frac{1}{6}(n-1)(n-2) \alpha_{1} t_{1}-\frac{h}{c t_{1}}\right]-\frac{2 b \alpha}{c t_{1}} s^{\alpha-1}\left(e^{c t_{1}}-1\right) \ldots \\
\frac{\partial^{2} A P}{\partial s \partial B}=\frac{1}{t_{1}}\left(e^{c t_{1}}-1\right) \ldots
\end{gathered}
$$

To maximize average profit per unit time $A P(s, B)$, the optimal values of sand $B$ can be obtained by solving the following equations simultaneously.

$$
\frac{\partial A P}{d s}=0 \quad \text { and } \quad \frac{\partial A P}{d B}=0
$$

i.e. $\frac{\partial A P}{\partial B}=\left(e^{c t_{1}}-1\right)\left[\frac{\left(s-c_{1}\right)}{t_{1}}-\frac{(n-1)}{2} h_{1}-\frac{1}{6}(n-1)(n-2) \alpha_{1} t_{1}-\frac{h}{c t_{1}}\right]=0$

and $\frac{\partial A P}{\partial s}=-\frac{h b \alpha}{c} s^{\alpha-1}-\frac{b \alpha}{c} s^{\alpha-1}\left(e^{c t_{1}}-1\right)\left[\frac{\left(s-c_{1}\right)}{t_{1}}-\frac{(n-1)}{2} h_{1}-\frac{1}{6}(n-1)(n-2) \alpha_{1} t_{1}\right.$

$$
\left.-\frac{h}{c t_{1}}\right]+\frac{1}{t_{1}}\left\{B+\frac{\left(a-b s^{\alpha}\right)}{c}\right\}\left(e^{c t_{1}}-1\right)=0
$$

provided $r t-s^{2}=\left(\frac{\partial^{2} A P}{\partial B^{2}}\right)\left(\frac{\partial^{2} A P}{\partial s^{2}}\right)-\left(\frac{\partial^{2} A P}{\partial s \partial B}\right)^{2}$

$$
=-\left(\frac{\partial^{2} A P}{\partial s \partial B}\right)^{2}<0
$$

The results show that $A P(s, B)$ is a concave function of $s$ and $B$ for fixed $\mathrm{n}$ and $t_{1}$. Therefore, there exists a unique value of sand $B$ such that $A P(s, B)$ is maximum.

CASE 2: If $\mathrm{c}=0$, then the demand rate reduces to $D\left(A_{D}, s, I(t)\right)=A_{D}^{\beta}\left(a-b s^{\alpha}\right), \quad 0<t \leq t_{1}$. That is, the demand rate depends on frequency of advertisement and unit selling price.

Hence, the inventory level at time $t$ is given by the differential equation :

$$
\frac{d I(t)}{d t}=-\left[A_{D}^{\beta}\left(a-b s^{\alpha}\right)\right]
$$

Therefore,

$$
I(t)=B+A_{D}^{\beta}\left(a-b s^{\alpha}\right)\left(t_{1}-t\right)
$$

And the quantity per transfer from the warehouse to the display area is given by

$$
q=A_{D}^{\beta}\left(a-b s^{\alpha}\right) t_{1} \ldots
$$

and the average profit per unit time $A P(s, B)$ over the period $[0, \mathrm{~T}]$ is reduced to

$$
\begin{gathered}
A P(s, B)=-\frac{A}{n t_{1}}-\frac{A_{t}}{t_{1}}-h B+A_{D}^{\beta}\left(a-b s^{\alpha}\right)\left[\frac{\left(s-c_{1}\right)}{n}\right. \\
\left.-\frac{1}{2}(n-1) h_{1}-\frac{1}{6}(n-1)(n-2) \alpha_{1} t_{1}-\frac{t_{1}}{2 n}\right] \ldots
\end{gathered}
$$


Taking the first order partial derivative of $A P(s, B)$ with respect to $B$, we get

$$
\frac{\partial A P}{\partial B}=-h<0 \ldots
$$

It shows that $\mathrm{AP}$ is a decreasing function of $\mathrm{B}$. Therefore, the optimal retransfer level of the item in the display area $\mathrm{B} *$ should be zero.

Substituting $\mathrm{B}^{*}=0$ into equation $(27)$, we obtain $A P(s, B)$ as a function of sas follows:

$$
A P(s, B)=-\frac{A}{n t_{1}}-\frac{A_{t}}{t_{1}}+A_{D}^{\beta}\left(a-b s^{\alpha}\right)\left[\frac{\left(s-c_{1}\right)}{n}-\frac{1}{2}(n-1) h_{1}-\frac{1}{6}(n-1)(n-2) \alpha_{1} t_{1}-\frac{t_{1}}{2 n}\right] \ldots
$$

Taking the first and second partial derivative of $A P(s, B)$ with respect to $s$ we obtain

$$
\frac{\partial A P}{\partial s}=-b \alpha A_{D}^{\beta} s^{\alpha-1}\left[\frac{\left(s-c_{1}\right)}{n}-\frac{(n-1)}{2} h_{1}-\frac{1}{6}(n-1)(n-2) \alpha_{1} t_{1}-\frac{t_{1}}{2 n}\right]+\frac{1}{n} A_{D}^{\beta}\left(a-b s^{\alpha}\right) \ldots
$$

And $\frac{\partial^{2} A P}{\partial s^{2}}=-b \alpha(\alpha-1) A_{D}^{\beta} s^{\alpha-2}\left[\frac{\left(s-c_{1}\right)}{n}-\frac{(n-1)}{2} h_{1}\right.$

$$
\left.-\frac{1}{6}(n-1)(n-2) \alpha_{1} t_{1}-\frac{t_{1}}{2 n}\right]-\frac{2 b \alpha A_{D}^{\beta}}{n} s^{\alpha-1}<0 \ldots
$$

Provided $\left[\frac{\left(s-c_{1}\right)}{n}-\frac{(n-1)}{2} h_{1}-\frac{1}{6}(n-1)(n-2) \alpha_{1} t_{1}-\frac{t_{1}}{2 n}\right]>0$

The results show that $A P(s, B)$ is a concave function of $s$ for fixed $\mathrm{n}$ and $t_{1}$. Therefore, there exists a unique value of $s$ such that $A P(s, B)$ is maximum.

\section{CASE 3:}

If $\beta=\mathrm{b}=\alpha_{1}=0$, then the demand rate reduces to $D\left(A_{D}, s, I(t)\right)=(a+c I(t)), \quad 0<t \leq t_{1}$.

That is, the demand rate depends only on instantaneous displayed stock level and the model reduces to Goyal and Chang (2009). In the proposed model

1. The total cost per unit cycle in the warehouse

The total cost over the period $[0, \mathrm{~T}]$ in the warehouse consists of

(i) the cost of placing orders $=\mathrm{A}$

(ii) the cost of stock holding, $C_{w h}=\sum_{j=1}^{n-1} h_{1}(n-j) q t_{1}$

$$
=\frac{1}{2} n(n-1) h_{1} q t_{1}
$$

2. The total cost per unit cycle in the display area

The inventory level at time $\mathrm{t}$ is given by the differential equation :

$$
\frac{d I(t)}{d t}=-(a+c I(t))
$$

Therefore,

$$
I(t)=B e^{c\left(t_{1}-t\right)}+\frac{a}{c}\left\{e^{c\left(t_{1}-t\right)}-1\right\}
$$

And the quantity per transfer from the warehouse to the display area is given by

$$
q=\left\{B+\frac{a}{c}\right\}\left(e^{c t_{1}}-1\right) \ldots
$$

Then the total cost of stock holding in the warehouse is

$$
C_{w h}=\frac{1}{2} n(n-1) h_{1}\left\{B+\frac{a}{c}\right\}\left(e^{c t_{1}}-1\right) t_{1}
$$

and the average profit per unit time $A P(s, B)$ over the period $[0, \mathrm{~T}]$ is

$$
A P(s, B)=-\frac{A}{n t_{1}}-\frac{A_{t}}{t_{1}}+h \frac{a}{c}+\left\{B+\frac{a}{c}\right\}\left(e^{c t_{1}}-1\right)\left[\frac{\left(s-c_{1}\right)}{t_{1}}-\frac{1}{2}(n-1) h_{1}-\frac{h}{c t_{1}}\right]
$$


This reduces to the result of model proposed by Goyal and Chang (2009).

\section{Numerical Example}

Example1: When demand rate depends on unit selling price, instantaneous displayed stock level and frequency of advertisement, a practical model is considered taking the following values for different parameters:

Cost per transfer from the warehouse to the display area $A_{t}=$ Rs. 100 , Ordering cost $\mathrm{A}=$ Rs. 200/order, Item cost $c_{1}=$ Rs. 5 per unit, Holding cost in the warehouse $h_{1}=0.6$ per unit, Holding cost in the display area $h=0.5$ per unit, $\mathrm{a}=575, \mathrm{~b}=$ $28, \mathrm{c}=0.2, \alpha=1.2, \alpha_{1}=0.2, \beta=0.02$, frequency of advertisements in the cycle $A_{D}=4, \mathrm{n}=3$ and $t_{1}=4$

Using the solution procedure described above the results obtained are, the selling price $s=$ Rs.10.90 for which Average profit $A P(s, B)$ becomes maximum. Hence the optimum values of s and B are Rs.10.90 and 9.6605 respectively, and the maximum Average profit $A P\left(s^{*}, B^{*}\right)=$ Rs. 165.77. We then have $T^{*}=n t_{1}=12, q^{*}=541.77$ and $Q=n q=1625.31$

Example2: Based on Case 1, when demand rate depends on unit selling price and instantaneous displayed stock level, a practical model is considered taking the following values for different parameters:

Cost per transfer from the warehouse to the display area $A_{t}=$ Rs. 100 , Ordering cost $\mathrm{A}=$ Rs. 200/order, Item cost $c_{1}=$ Rs. 5 per unit, Holding cost in the warehouse $h_{1}=0.6$ per unit, Holding cost in the display area $h=0.5$ per unit, $\mathrm{a}=575, \mathrm{~b}=$ $28, \mathrm{c}=0.2, \alpha=1.2, \alpha_{1}=0.2, \beta=0$, frequency of advertisements in the cycle $A_{D}=4, \mathrm{n}=3$ and $t_{1}=4$

Using the solution procedure described above the results obtained are, the selling price $\mathrm{s}=$ Rs.10.97 for which Average profit $A P(s, B)$ becomes maximum. Hence the optimum values of s and B are Rs.10.97 and 46.279 respectively, and the maximum Average profit $A P\left(s^{*}, B^{*}\right)=$ Rs. 156.5. We then have $T^{*}=n t_{1}=12, q^{*}=542.43$ and $Q=n q=1627.29$

Example3: Based on Case 2, when demand rate depends on frequency of advertisement and unit selling price, a practical model is considered taking the following values for different parameters:

Cost per transfer from the warehouse to the display area $A_{t}=$ Rs. 100 , Ordering cost $\mathrm{A}=\mathrm{Rs} .200 /$ order, Item cost $c_{1}=$ Rs. 4 per unit, Holding cost in the warehouse $h_{1}=0.6$ per unit, Holding cost in the display area $h=0.5$ per unit, $\mathrm{a}=575, \mathrm{~b}=$ $28, \mathrm{c}=0, \alpha=1.2, \alpha_{1}=0.2, \beta=0.02$, frequency of advertisements in the cycle $A_{D}=4, \mathrm{n}=3$ and $t_{1}=4$

Using the solution procedure described above the results obtained are, the selling price $s=$ Rs.10.52 for which Average profit $A P(s, B)$ becomes maximum. Hence the optimum values of $\mathrm{s}$ is Rs.10.52, and the maximum Average profit $A P\left(s^{*}, B^{*}\right)=$ Rs. 26.37. We then have $T^{*}=n t_{1}=12, q^{*}=424.99$ and $Q=n q=1274.97$

\section{Sensitivity Analysis}

To study the effect of changes of the parameters on the optimal profit derived by proposed method, a sensitivity analysis is performed considering the numerical examples given above. Sensitivity analysis is performed by changing (increasing or decreasing) the parameters by $20 \% \& 50 \%$ and taking one parameter at a time, keeping the remaining parameters at their original values. The results are shown in Table 1, Table $2 \&$ Table 3 for Examples1, $2 \& 3$ respectively.

\section{A careful study of Table 1 reveals the following:}

1. $s$ is slightly sensitive to changes in the values of parameter $h_{1}, \alpha_{1} \& c$, it is moderately sensitive to changes in $\mathrm{h}$ and neutral to changes in $b \& \alpha$.

2. $B$ is highly sensitive to changes in $h, h_{1}, \alpha, \alpha_{1}, b \& c$.

3. $q$ is slightly sensitive to changes in the values of parameters $h, h_{1} \& \alpha_{1}$, it is moderately sensitive to changes in $b$ \& $c$ and highly sensitive to changes in $\alpha$.

4. AP is slightly sensitive to changes in the values of parameters $h, c \& \alpha_{1}$, it is moderately sensitive to changes in $b$ $\& h_{1}$ and highly sensitive to changes in $\alpha$

\section{A careful study of Table 2 reveals the following:}

1. $s$ is slightly sensitive to changes in the values of parameter $h, h_{1}, \alpha_{1} \& c$ and neutral to changes in $b \& \alpha$.

2. $B$ is moderately sensitive to changes in $h_{1} \& \alpha_{1}$ highly sensitive to changes in $h, \alpha, b \& c$.

3. $q$ is slightly sensitive to changes in the values of parameters $h, h_{1}, b, c \& \alpha_{1}$ and highly sensitive to changes in $\alpha$.

4. AP is slightly sensitive to changes in the values of parameters $h, h_{1} \& \alpha_{1}$, it is moderately sensitive to changes in $b$ $\& c$ and highly sensitive to changes in $\alpha$ 


\section{A careful study of Table 3 reveals the following:}

1. $s$ is slightly sensitive to changes in the values of parameter $h_{1}, \alpha_{1} \& b$, it is highly sensitive to changes in $\alpha$ and neutral to changes in $h$.

2. $\mathrm{q}$ is slightly sensitive to changes in the values of parameters $h_{1}, \alpha_{1} \& b$, it is moderately sensitive to changes in $\alpha$ and neutral to changes in $h$.

3. AP is slightly sensitive to changes in the values of parameters $h_{1} \& \alpha_{1}$, it is highly sensitive to changes in $b \& \alpha$ and neutral to changes in $h$.

\section{Conclusions}

In this paper, an ordering-transfer inventory model is developed when the amount of display area is limited and warehouse is taken to store the items. The demand rate depends on unit selling price, instantaneously displayed stock level and frequency of advertisement. A time dependent holding cost for the rented warehouse is considered in the model. Optimal selling price, optimal buffer stock, ordering quantity and optimal number of units transferred from the rented warehouse to the display area for maximizing the average profit per unit are determined. Results obtained imply that the effect of time dependent holding cost, three component demand rate and concept of buffer stock on the average profit is more significant than a policy which ignores the effects of these factors. An analytic formulation of the problem on the frame work described above and an optimal solution procedure to find optimal ordering transfer policy is presented. Sensitivity analysis with respect to various parameters has been carried out.

Thus this model incorporates some realistic features that are likely to be associated with some kind of inventory. The model could be very useful in retail business. It can be used for electronic components, fashionable goods, clothes and other products which have more likely the characteristics above.

The present study can be further extended for some other factors involved in the inventory system.

\section{Appendix}

Let $\frac{d I(t)}{d t}=-D\left(A_{D}, s, I(t)\right)$

Where $D\left(A_{D}, s, I(t)\right)=A_{D}^{\beta}\left(a-b s^{\alpha}+c I(t)\right)$

Let $\lambda=A_{D}^{\beta}\left(a-b s^{\alpha}\right)$ and $\mu=A_{D}^{\beta} c$

Then $D\left(A_{D}, s, I(t)\right)=\lambda+\mu I(t)$

$$
\begin{gathered}
\frac{d I(t)}{d t}=-\{\lambda+\mu I(t)\} \\
I(t)=-\frac{\lambda}{\mu}+x e^{-\mu t}
\end{gathered}
$$

Where $x$ is any constant of integration

Using boundary condition $I\left(t_{1}\right)=B$ we get

$$
x=e^{\mu t_{1}}\left(B+\frac{\lambda}{\mu}\right)
$$

Thus, $I(t)=B e^{\mu\left(t_{1}-t\right)}+\frac{\lambda}{\mu}\left\{e^{\mu\left(t_{1}-t\right)}-1\right\}$

Hence $I(t)=B e^{A_{D}^{\beta} c\left(t_{1}-t\right)}+\frac{\left(a-b s^{\alpha}\right)}{c}\left\{e^{A_{D}^{\beta} c\left(t_{1}-t\right)}-1\right\}$

\section{References}

Alfares, H.K. (2007). An Inventory model with stock-level dependent demand rate and variable holding cost, International Journal of Production Economics, 108, 259-265.

Bhunia, A.K. and Maiti, M. (1998). A two warehouse inventory model for deteriorating items with a linear trend in demand and shortages, Journal of the Operational Research Society, 49(3), 287-292.

Burwell, T.H., Dave, D.S., Fitzpatrick, K.E. and Roy, M.R. (1997). Economic lot size model for price dependent demand under quantity and freight discounts, International Journal of Production Economics, 48, 141-155.

Dey, J.K., Mondal, S.K. and Maiti, M. (2008). Two storage inventory problem with dynamic demand and interval valued lead-time over finite time horizon under inflation and time-value of money, European Journal of Operational Research, $185,170-194$.

Dutta, T.K. and Pal, A.K. (1990). A note on inventory model with inventory level dependent demand rate, Journal of Operational Research Society, 41, 971-975. 
Giri, B.C. and Chaudhari, K.S. (1998). Deterministic models of perishable inventory with stock-dependent demand rate and non-linear holding cost, European Journal of Operational Research, 105, 467-474.

Goh, M. (1994). EOQ model models with general demand and holding cost functions, European Journal of Operational Research, 73(1), 50-54.

Goswami, A. and Chaudhuri, K.S. (1992). An Economic order quantity model for items with two levels of storage for a linear trend in demand, Journal of Operational Research Society, 43, 157-167.

Goyal, S.K. (1977). An integrated inventory model for a single supplier - single customer problem, International Journal of Production Economics, 15, 107-111.

Goyal, S.K. and Chang, C.T. (2009). Optimal ordering and transfer policy for an inventory with stock dependent demand, European Journal of Operational Research, 196, 177-185.

Gupta, R. and Vrat, P. (1986).Inventory model for stock dependent consumption rate, Opsearch, 23, 19-24.

Gupta, R.K., Bhunia, A.K. and Goyal, S.K. (2007). An application of genetic algorithm in a marketing oriented inventory model with interval valued inventory cost and three component demand rate dependent on displayed stock level, Applied Mathematics and Computation, 192(2), 466-478.

Ishii, H. and T. Nose. (1996). Perishable inventory control with two types of customers and different selling prices under the warehouse capacity constraint, International Journal of Production Economics, 44, 167-176.

Kar, S., Bhunia, A.K. and Maiti, M. (2001). Deterministic inventory model with two levels of storage, a linear trend in demand and a fixed time horizon, Computers $\mathcal{E}$ Operations Research, 28, 1315-1331.

Levin, R.I., Mclaughin, C.P., Lamone, R.P. and Kottas, J.F. (1972). Contemporary policy for managing operating system, Productions/Operations Management, Mc-Graw Hill, New York.

Maity, A.K., Maity, K. and Maiti, M. (2008). A production recycling inventory system with imprecise holding costs, Applied Mathematical Modeling, 32, 2241-2253.

Mandal, B.N. and Phaujdar, S. (1989). An inventory model for deteriorating items and stock dependent consumption rate, Journal of Operational Research Society, 40, 483-488.

Mo, J.T., Mi, F., Zhou, F. and Pan, H. (2009). A note on an EOQ model with stock and price sensitive demand, Mathematical and Computer Modeling, 49, 2029-2036.

Muhlemann, A.P. and Spanopoulos, N.P.V. (1980). A variable holding cost EOQ model, European Journal of Operational Research, 4, 132-135.

Murdeshwar, T.A. and Sathe, Y.S. (1985). Some aspect of lot size model with two levels of storage, Opsearch, 22, 255-262.

Padmanabhan, G. and Vrat, P. (1995). EOQ model for perishable items under stock dependent selling rate, European Journal of Operational Research, 86, 281-292.

Pakkala, T.P.M. and Achary, K.K. (1991). A two warehouse probabilistic order level inventory model for deteriorating items, Journal of the Operational Research Society, 42, 1117-1122.

Pal, A.K., Bhunia, A.K. and Mukherjee, R.N. (2006). Optimal lot size model for deteriorating items with demand rates dependent on displayed stock level and partial back-ordering, European Journal of Operational Research, 175, 977-991.

Shao, Y.E., Fowler, J.W. and Runger, G.C. (2000). Determining the optimal target for a process with multiple markets, International Journal of Production Economics, 65, 229-242.

Teng, J.T. and Chang, C.T. (2005). Economic production quantity models for deteriorating items with price and stock dependent demand, Computers and Operations Research, 32(2), 297-308.

Urban, T.L. (2008). An extension of inventory models with discretely variable holding costs, International Journal of Production Economics, 114, 399-403.

Wee, H.M. (2005c). Two-warehouse inventory model with partial backordering and weibull distribution deterioration under inflation, Journal of the Chinese Institute of Industrial Engineers, 22(6), 451- 462.

Weiss, H. (1982). Economic order quantity models with non linear holding cost, European Journal of Operational Research, 9, 56-60.

Yang, H.L. (2004). Two warehouse inventory models for deteriorating items with shortages under inflation, European Journal of Operational Research, 157(2), 344-356. 
Table 1.

\begin{tabular}{|c|c|c|c|c|c|}
\hline Parameter & $\begin{array}{l}\% \text { change in } \\
\mathrm{h}\end{array}$ & $\begin{array}{l}\% \text { change in } \\
\mathrm{s}\end{array}$ & $\begin{array}{l}\% \text { change in } \\
\mathrm{B}\end{array}$ & $\begin{array}{l}\% \text { change in } \\
q\end{array}$ & $\begin{array}{l}\% \text { change in } \\
\text { AP }\end{array}$ \\
\hline \multirow[t]{4}{*}{$\mathrm{h}$} & -50 & -0.1116 & -56.1855 & -0.5117 & -0.1347 \\
\hline & -20 & -0.0446 & -22.6836 & -0.2073 & 0.0662 \\
\hline & 20 & 0.0446 & 22.9482 & 0.2105 & -0.2287 \\
\hline & 50 & 0.1116 & 57.8428 & 0.5321 & -0.8806 \\
\hline \multirow[t]{4}{*}{$h_{1}$} & -50 & -0.1101 & -34.2797 & -0.0231 & 0.9693 \\
\hline & -20 & -0.0367 & -11.5019 & -0.0075 & 0.3256 \\
\hline & 20 & 0.0367 & 11.5748 & 0.0072 & -0.3280 \\
\hline & 50 & 0.1101 & 34.9361 & 0.0211 & -0.9910 \\
\hline \multirow[t]{4}{*}{$\mathrm{b}$} & -50 & 0.0000 & -149.3018 & -0.5000 & 3.7101 \\
\hline & -20 & 0.0000 & -59.7208 & -0.2000 & 1.4840 \\
\hline & 20 & 0.0000 & 59.7208 & 0.2000 & -1.4841 \\
\hline & 50 & 0.0000 & 149.3017 & 0.5000 & -3.7102 \\
\hline \multirow[t]{4}{*}{$\mathrm{c}$} & -50 & 0.2231 & 281.9056 & 1.0822 & -2.8061 \\
\hline & -20 & 0.0558 & 42.8687 & 0.2636 & -0.3115 \\
\hline & 20 & -0.0372 & -18.6654 & -0.1729 & 0.0663 \\
\hline & 50 & -0.0744 & -29.5422 & -0.3436 & 0.0210 \\
\hline \multirow[t]{4}{*}{$\alpha$} & -50 & 0.0000 & -232.6122 & -0.8807 & 5.6502 \\
\hline & -20 & 0.0000 & -135.2405 & -0.5491 & 3.2376 \\
\hline & 20 & 0.0000 & 246.7263 & 1.1288 & -5.7437 \\
\hline & 50 & 0.0000 & 1045.2295 & 5.2878 & -23.6853 \\
\hline \multirow[t]{4}{*}{$\alpha_{1}$} & -50 & -0.0489 & -15.3194 & -0.0100 & 0.4336 \\
\hline & -20 & -0.0196 & -6.1435 & -0.0040 & 0.1739 \\
\hline & 20 & 0.0196 & 6.1643 & 0.0039 & -0.1747 \\
\hline & 50 & 0.0489 & 15.4489 & 0.0096 & -0.4379 \\
\hline
\end{tabular}

Table 2 .

\begin{tabular}{|c|c|c|c|c|c|}
\hline Parameter & $\begin{array}{l}\% \text { change in } \\
\mathrm{h}\end{array}$ & $\begin{array}{l}\% \text { change in } \\
\mathrm{s}\end{array}$ & $\begin{array}{l}\% \text { change in } \\
\mathrm{B}\end{array}$ & $\begin{array}{l}\% \text { change in } \\
\mathrm{q}\end{array}$ & $\begin{array}{l}\% \text { change in } \\
\text { AP }\end{array}$ \\
\hline \multirow[t]{4}{*}{$h$} & -50 & -0.1140 & -12.1359 & -0.5120 & -0.0979 \\
\hline & -20 & -0.0456 & -4.9006 & -0.2074 & 0.0918 \\
\hline & 20 & 0.0456 & 4.9591 & 0.2108 & -0.2690 \\
\hline & 50 & 0.1140 & 12.5019 & 0.5327 & -1.0096 \\
\hline \multirow[t]{4}{*}{$h_{1}$} & -50 & -0.1094 & -7.1725 & -0.0229 & 1.0281 \\
\hline & -20 & -0.0365 & -2.4064 & -0.0074 & 0.3453 \\
\hline & 20 & 0.0365 & 2.4215 & 0.0072 & -0.3479 \\
\hline & 50 & 0.1094 & 7.3082 & 0.0210 & -1.0509 \\
\hline \multirow[t]{4}{*}{$b$} & -50 & 0.0000 & -31.5616 & -0.5000 & 3.9595 \\
\hline & -20 & 0.0000 & -12.6246 & -0.2000 & 1.5838 \\
\hline & 20 & 0.0000 & 12.6246 & 0.2000 & -1.5838 \\
\hline & 50 & 0.0000 & 31.5616 & 0.5000 & -3.9595 \\
\hline \multirow[t]{4}{*}{$c$} & -50 & 0.2280 & 61.4681 & 1.0839 & -3.1597 \\
\hline & -20 & 0.0570 & 9.4247 & 0.2639 & -0.3642 \\
\hline & 20 & -0.0380 & -4.1501 & -0.1731 & 0.0887 \\
\hline & 50 & -0.0760 & -6.6248 & -0.3437 & 0.0556 \\
\hline \multirow[t]{4}{*}{$\alpha$} & -50 & 0.0000 & -49.2580 & -0.8812 & 6.0370 \\
\hline & -20 & 0.0000 & -28.6717 & -0.5497 & 3.4619 \\
\hline & 20 & 0.0000 & 52.4273 & 1.1320 & -6.1508 \\
\hline & 50 & 0.0000 & 222.6025 & 5.3116 & -25.4019 \\
\hline \multirow[t]{4}{*}{$\alpha_{1}$} & -50 & -0.0486 & -3.2051 & -0.0099 & 0.4599 \\
\hline & -20 & -0.0195 & -1.2853 & -0.0039 & 0.1845 \\
\hline & 20 & 0.0194 & 1.2896 & 0.0039 & -0.1852 \\
\hline & 50 & 0.0486 & 3.2319 & 0.0096 & -0.4644 \\
\hline
\end{tabular}


Table 3.

\begin{tabular}{|l|l|l|l|l|}
\hline Parameter & \% change in $\mathrm{h}$ & \% change in s & \% change in q & $\begin{array}{l}\text { \% change in } \\
\text { AP }\end{array}$ \\
\hline$h$ & -50 & 0.0000 & 0.0000 & 0.0000 \\
\hline & -20 & 0.0000 & 0.0000 & 0.0000 \\
\hline & 20 & 0.0000 & 0.0000 & 0.0000 \\
\hline$h_{1}$ & 50 & 0.0000 & 0.0000 & 0.0000 \\
\hline & -50 & -0.0419 & 0.2285 & 1.3473 \\
\hline & -20 & -0.0140 & 0.0765 & 0.4184 \\
\hline & 20 & 0.0140 & -0.0768 & -0.3875 \\
\hline$b$ & 50 & 0.0421 & -0.2316 & -1.0692 \\
\hline & -50 & 0.4717 & 0.9357 & 15.3177 \\
\hline & -20 & 0.1227 & 0.3689 & 3.3250 \\
\hline & 20 & -0.0842 & -0.3644 & -1.6962 \\
\hline$\alpha$ & 50 & -0.1706 & -0.9053 & -2.5642 \\
\hline & -50 & 6.1910 & 0.9317 & 171.4017 \\
\hline & -20 & 0.5128 & 0.7035 & 14.1599 \\
\hline & 20 & -1.0000 & -1.0000 & -1.0000 \\
\hline$\alpha_{1}$ & 50 & -1.0000 & -1.0000 & -1.0000 \\
\hline & -50 & -0.0186 & 0.1019 & 0.5647 \\
\hline & -20 & -0.0075 & 0.0408 & 0.2193 \\
\hline & 20 & 0.0075 & -0.0409 & -0.2105 \\
\hline & 50 & 0.0187 & -0.1025 & -0.5097 \\
\hline
\end{tabular}

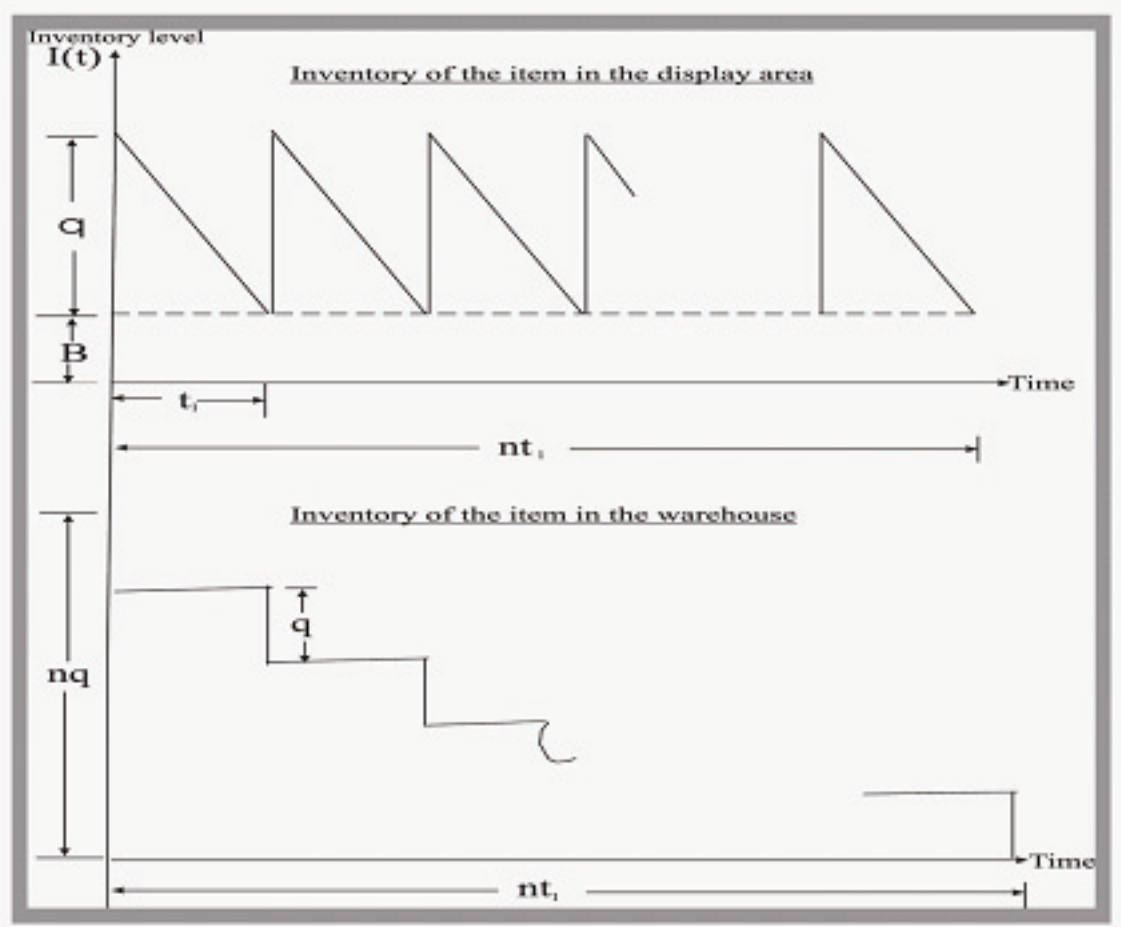

Figure 1. 